\title{
Duration of untreated psychiatric illness and its correlations in patients attending a tertiary care psychiatric facility: a cross- sectional study
}

\author{
Swarna Buddha Nayok ${ }^{1 *}$, Sathyanarayana $\mathrm{MT}^{2}$, Dhanashree Akshatha H.S. ${ }^{3}$
}

\section{ABSTRACT}

Introduction: Duration of untreated psychiatric illness is an important component of the final pathway to care for patients. Longer the duration of untreated illness, poorer is the prognosis. Aim: To determine the Duration of Untreated Illness (DUI) along with its correlates, to thus evaluate the pathway to care at our setup. Settings and design: A retrospective crosssectional study including 228 patients with psychiatric illnesses done at a tertiary care general hospital with a psychiatric setup. Materials: Semi-structured proforma for socio-demographic details, psychiatric diagnosis, duration of illness and duration of untreated illness. Statistical analysis: Sociodemographic details were mainly descriptive and categories compared using Pearson's Chi square test. Results: The mean age of patients was 36.13 years (Standard Deviation (S.D.) 15.06). The mean DUI was 57.53 months (80.21). Excluding patients with Alcohol Dependence Syndrome (ADS), mean duration of illness was 51.58 months (S.D. 75.50) and DUI was 33.77 months (S.D. 49.11). Mean duration of illness for ADS group was 176.19 months (S.D. 101.20) and DUI was 165.90 months (S.D. 103.07). There was significant association of DUI with occupation $(\mathrm{P}=.039)$ and residence $(\mathrm{P}=.006)$. While $127(55.70 \%)$ of patients showed to a psychiatrist at first, seventy $(30.7 \%)$ patients went to faith healers first. Conclusion: It took about 5 years on average to reach a psychiatric facility, which was higher in patients with ADS. Awareness regarding illness model of ADS and other psychiatric disorders along treatment availability may improve DUI and lead to better prognosis.

\section{Keywords: Duration of untreated illness, Pathway to care, Psychiatric illness}

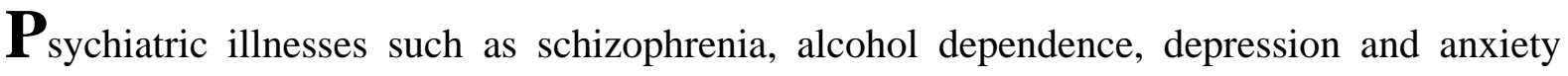
disorders affect more than a billion people worldwide. Together, they contribute to a significant amount of burden, which when expressed in terms of Disability Adjusted Life

\footnotetext{
${ }^{1}$ Junior Resident, Department of Psychiatry, Sri Siddhartha medical College and Hospital, Tumakuru, Karnataka, India

${ }^{2}$ Professor and Head, Department of Psychiatry, Sri Siddhartha medical College and Hospital, Tumakuru, Karnataka, India

${ }^{3}$ Assistant Professor, Department of Psychiatry, Sri Siddhartha medical College and Hospital, Tumakuru, Karnataka, India

*Responding Author
} 


\section{Duration Of Untreated Psychiatric Illness And Its Correlations In Patients Attending A Tertiary Care Psychiatric Facility: A Cross-Sectional Study}

Years (DALY) comes to about $7 \%$ of overall global burden (Rehm \& Shield, 2019). In India, 197 million people are affected by psychiatric illness. This has led to an increase in burden and disability as well. DALY has increased by about $2 \%$ in last three decades in India (Sagar et al., 2020). This shows the need for adequate detection and treatment of psychiatric illnesses. The prognosis of these disorders depends on socio-demographic factors, illness factors and management related factors. A significant factor associated with prognosis is called "pathway of care". This, in simpler terms, describes the process of treatment seeking from the patients' side, thus outlining a pathway taken by them or their caregivers to reach an adequate treatment providing setup (McGlashan, 1999; Salins et al., 2017; Schrijvers et al., 2012). This is invariably poor in India, often showing that patients take a long time to reach appropriate psychiatric care facilities. This is again related to the poor insight and stigma associated with most psychiatric illnesses along with financial and logistical difficulties. The first contact is often with indigenous and magico-religious or faith healers. By the time the patient receives proper psychiatric treatment, he or she would have had a long duration of untreated illness. The longer the patient remains without adequate treatment, worse in the outcome (Grover et al., 2016; Jeyashree et al., 2013).

Out of 295 patients evaluated at a speciality psychiatric hospital in central India, only about $9 \%$ had their first visit to a psychiatrist before, majority consulting faith healers at first. It took about 21 months of mean time for the patients to reach a psychiatric facility (Lahariya et al., 2010). In a cross-sectional study from northern India, at a general hospital with a psychiatric OPD, 225 patients were evaluated. Patients reached there about 2 years (median) after illness onset and only about $15 \%$ came to the psychiatrist first (Gupta, 2012). A similar study from western India showed a median duration of 6 months, while evaluating 76 patients (Jain et al., 2012). While evaluating the same issue regarding a community mental health care in northern India, mean duration for the patients to reach the facility was about 23 months (Singh et al., 2018). When the patient population was restricted to only bipolar disorder, the percentage of patients visiting to a psychiatrist at first was higher, about 43\% (Sahu et al., 2019). While evaluating patients with Dhat syndrome, a higher duration of about 6 years of untreated illness was found, with patients first visiting indigenous healers (Grover et al., 2016).

While pathway of care has been studied, it may have been limited to well-known psychiatric care centres (Lahariya et al., 2010). Our hospital is a general hospital and is situated in one of the district head-quarters in a southern Indian state. While there are well-known psychiatric facilities at the state capital, it may be difficult of patients from rural areas to access them due to logistics. In that way, our centre serves as both as a tertiary care general hospital with psychiatric facility and a relay centre to higher and more reputed institutions catering exclusively to patients with psychiatric illnesses. Thus, we aim to determine the Duration of Untreated Illness (DUI) along with its correlates, to thus evaluate the pathway to care at our setup.

\section{METHODOLOGY}

\section{Participants}

This was a retrospective cross-sectional analysis undertaken at a private medical college attached to a tertiary care private hospital. The department of psychiatry caters to about 40-50 out-patients every day. It also a thirty bedded in-patients facility for both genders, with about $80 \%$ bed occupancy rate. The psychiatry records of patients visiting psychiatry out-patients 


\section{Duration Of Untreated Psychiatric Illness And Its Correlations In Patients Attending A Tertiary Care Psychiatric Facility: A Cross-Sectional Study}

(OPD) from January 2019 to December 2019 were evaluated and included. We excluded those patients whose records were unclear regarding the necessary information.

\section{Procedure}

A data collection proforma was prepared to collect the socio-demographic details of the patients. Along with that, their diagnosis, duration of illness, first medical contact due to the psychiatric symptoms were evaluated from detailed psychiatric workups. The duration of illness before the first medical contact made was divided into groups of less than 1 month, more than one month but less than 6 months, more than 7 months but less than 12 months, more than 13 months but less than 60 months and more than 60 months. We evaluated 228 patient profiles after excluding 11 records due to incomplete information.

\section{Statistical analysis}

The data was compiled and analyzed using Statistical Package for the Social Sciences (SPSS) version 20. The analysis was mainly descriptive. To compare between categories like sociodemographic categories, psychiatric diagnosis and duration before contact, we used Pearson's Chi square test.

\section{RESULTS}

The sociodemographic descriptive details are given in Table 1. The mean age of patients was 36.13 years (Standard Deviation (S.D.) 15.06). The mean duration of illness was 73.99 months (S.D. 93.67). We considered the start of chief complaints till the first psychiatric visit to be the DUI. The mean DUI was 57.53 months (80.21). We further removed patients with ADS, as they had a longer DUI and illness duration as well. Excluding ADS, mean duration of illness was 51.58 months (S.D. 75.50) and DUI was 33.77 months (S.D. 49.11). Mean duration of illness for ADS group was 176.19 months (S.D. 101.20) and DUI was 165.90 months (S.D. 103.07).

We divided the psychiatric diagnoses into groups as Alcohol Dependence Syndrome (ADS) with uncomplicated withdrawal, delirious withdrawal or withdrawal associated with seizures, Schizophrenia and psychotic spectrum group, which included, schizoaffective disorder, delusional disorder and psychosis not otherwise classified (NOS), a separate group of acute and transient psychiatric disorder (ATPD), Bipolar disorder (BPD) with one group of current episode of mania or hypomania and the other group included mixed and depression. Depression related group which included depression in all severity, dysthymia, recurrent depressive disorder and mixed anxiety disorder, Anxiety group of panic disorder, agoraphobia, social phobia, generalised anxiety disorder (GAD) specific phobia and anxiety NOS, Obsessive-Compulsive Disorder (OCD) group and others, details of which are given in Table 2. We kept BPD mania and ATPD separate as these disorders had more chances of an acute presentation which may lead to a different pathway to care.

The correlates of sociodemographic categories and diagnosis with DUI is given in Table 1. We found significant association of DUI with occupation $(P=.039)$ and residence $(P=$ $.006)$. Most females $(72.38 \%)$ were homemakers and most $(80.70 \%)$ had a rural residence.

While $127(55.70 \%)$ of patients showed to a psychiatrist at first, seventy (30.7\%) patients went to faith healers first. Eleven went to local pharmacy initially, nine went to doctors but not psychiatrist and only three went to alternative medicine practitioners. Eight patients went to more than one of these. Twenty-one patients (72.41\%) from schizophrenia group of 29 
patients visited faith healers first. All patients with ATPD visited faith healer first, which was the highest percentage diagnosis wise. Diagnosis wise DUI is given in Table 2. Diagnosis showed a significant positive correlation $(p<.000)$.

Table 1: Sociodemographic details and correlation with DUI

\begin{tabular}{|c|c|c|}
\hline Sociodemographic variables & $\mathbf{N}(\%)$ & P value \\
\hline $\begin{array}{l}\text { Gender: } \\
\text { Males } \\
\text { Females }\end{array}$ & $\begin{array}{l}123 \\
105\end{array}$ & .605 \\
\hline $\begin{array}{l}\text { Religion: } \\
\text { Hindu } \\
\text { Muslim } \\
\text { Christian }\end{array}$ & $\begin{array}{l}198 \\
28 \\
02\end{array}$ & .153 \\
\hline $\begin{array}{l}\text { Education: } \\
\text { Nil } \\
\text { Primary } \\
\text { Middle } \\
\text { Secondary } \\
\text { Senior secondary } \\
\text { Under graduates and post graduates }\end{array}$ & $\begin{array}{l}24 \\
14 \\
51 \\
64 \\
28 \\
47\end{array}$ & .933 \\
\hline $\begin{array}{l}\text { Occupation: } \\
\text { Farming and Fisheries } \\
\text { Homemaker } \\
\text { Service Workers, Shop Owners } \\
\text { Machine Operators } \\
\text { Unemployed } \\
\text { Unskilled Labourers } \\
\text { Students } \\
\text { Professionals } \\
\text { Retired } \\
\text { Business }\end{array}$ & $\begin{array}{l}22 \\
76 \\
32 \\
05 \\
37 \\
23 \\
10 \\
03 \\
09 \\
11\end{array}$ & $.039 *$ \\
\hline $\begin{array}{l}\text { Residence: } \\
\text { Rural } \\
\text { Urban }\end{array}$ & $\begin{array}{l}184 \\
44\end{array}$ & $.006^{* *}$ \\
\hline $\begin{array}{l}\text { Marital status: } \\
\text { Married } \\
\text { Unmarried } \\
\text { Divorced/Separated } \\
\text { Widowed }\end{array}$ & $\begin{array}{l}162 \\
60 \\
01 \\
05\end{array}$ & .863 \\
\hline \multicolumn{3}{|c|}{$\begin{array}{l}\text { Abbreviation: DUI: Duration of Untreated Illness } \\
* \text { Significant } \\
* * \text { Strongly significant }\end{array}$} \\
\hline
\end{tabular}


Table 2: Diagnosis, DUI and visit to faith healers.

\begin{tabular}{|l|l|l|l|l|l|l|l|}
\hline \multicolumn{1}{|c|}{ Diagnosis } & \multicolumn{1}{c|}{$\begin{array}{c}\text { Number } \\
(\%)\end{array}$} & \multicolumn{3}{c|}{ DUI } & $\begin{array}{c}\text { Faith } \\
\text { healers }\end{array}$ \\
\hline & & $\begin{array}{l}<1 \\
\text { month }\end{array}$ & $\begin{array}{l}1-6 \\
\text { months }\end{array}$ & $\begin{array}{l}7-12 \\
\text { months }\end{array}$ & $\begin{array}{l}13-60 \\
\text { months }\end{array}$ & $\begin{array}{l}>60 \\
\text { months }\end{array}$ & \\
\hline $\begin{array}{l}\text { ADS uncomplicated } \\
\text { withdrawal }\end{array}$ & $27(11.8)$ & 0 & 0 & 1 & 3 & 23 & 2 \\
\hline $\begin{array}{l}\text { ADS delirious } \\
\text { withdrawal }\end{array}$ & $12(5.3)$ & 0 & 0 & 0 & 1 & 11 & 2 \\
\hline $\begin{array}{l}\text { ADS withdrawal } \\
\text { with seizure }\end{array}$ & $02(0.9)$ & 0 & 0 & 0 & 1 & 1 & 1 \\
\hline Schizophrenia group & $29(12.7)$ & 3 & 8 & 6 & 8 & 4 & 21 \\
\hline ATPD & $04(1.8)$ & 4 & 0 & 0 & 0 & 0 & 4 \\
\hline Bipolar, mania & $10(4.4)$ & 5 & 4 & 0 & 1 & 0 & 9 \\
\hline $\begin{array}{l}\text { Bipolar, depression, } \\
\text { others }\end{array}$ & $11(4.8)$ & 2 & 0 & 2 & 5 & 2 & 8 \\
\hline Depression group & $34(14.9)$ & 5 & 10 & 5 & 10 & 4 & 4 \\
\hline Anxiety group & $27(11.8)$ & 3 & 5 & 2 & 10 & 7 & 3 \\
\hline OCD & $08(3.5)$ & 1 & 2 & 0 & 4 & 1 & 3 \\
\hline Headache & $17(7.5)$ & 1 & 4 & 2 & 6 & 4 & 0 \\
\hline Somatoform & $06(2.6)$ & 0 & 1 & 0 & 3 & 2 & 2 \\
\hline Personality & $03(1.3)$ & 1 & 0 & 0 & 1 & 1 & 2 \\
\hline Delirium & $01(0.4)$ & 1 & 0 & 0 & 0 & 0 & 1 \\
\hline Dementia & $04(1.8)$ & 1 & 0 & 1 & 2 & 0 & 0 \\
\hline Seizure disorder & $05(2.2)$ & 2 & 0 & 1 & 0 & 2 & 3 \\
\hline Childhood disorder & $06(2.6)$ & 0 & 1 & 0 & 1 & 4 & 2 \\
\hline Sexual related & $05(2.2)$ & 0 & 1 & 2 & 1 & 1 & 2 \\
\hline Adjustment & $14(6.1)$ & 5 & 5 & 4 & 0 & 0 & 1 \\
\hline Others & $03(1.3)$ & 0 & 1 & 0 & 1 & 1 & 0 \\
\hline Abbreviatin & & & & & & \\
\hline
\end{tabular}

Abbreviation- DUI: Duration of Untreated Illness, ADS: Alcohol Dependence Syndrome, ATPD: Acute and Transient Psychotic Disorder OCD: Obsessive Compulsive Disorder

\section{DISCUSSION}

This study aimed to determine DUI and its correlates. Mean DUI was 4.79 years and after excluding ADS was 2.81 years. This is similar to other studies (Gupta, 2012; Lahariya et al., 2010; Singh et al., 2018). The difference in overall DUI is mainly attributed to patients with ADS, which increases the mean DUI by about 2 years. ADS group, by itself has a longer DUI, of about 14 years. This can be attributed to the resisting tendencies of patients with ADS towards psychiatric treatment (Chand et al., 2013; Sartor et al., 2009). Three patients with ADS from this study came for treatment only after they had severe abdominal pain and was diagnosed to have pancreatitis. One person with ADS came to us only after he had a cerebrovascular accident. Thus, ADS patients may require more attention regarding to DUI, which may increase with awareness regarding treatment availability and illness status of ADS (Enoch \& Goldman, 2002; Sartor et al., 2009).

Nearly $70 \%$ of patients with schizophrenia and $100 \%$ of those with acute psychosis visited faith healer first, which is eerily similar to our study. There was no mention of ADS in this study. This shows that acute presentation of psychotic illness prompts towards a tendency to magico-religious treatment, often on the lines of trance and possession (Lahariya et al., 2010). 


\section{Duration Of Untreated Psychiatric Illness And Its Correlations In Patients Attending A Tertiary Care Psychiatric Facility: A Cross-Sectional Study}

Those who had BPD with mania, 50\% came to psychiatrist within 1 month of their illness onset although $90 \%$ went to faith healer first. This shows that acute conditions, but not remitting like ATPD, may prompt patients to relatives to come to psychiatrist. BPD mania may have a longer course as compared ATPD. The results are similar to a study related to BPD, where visit to psychiatrist was high (Sahu et al., 2019).

There is significant delay in psychiatric treatment, which may be correlated with diagnosis, residence and occupation. This delay transforms as poor prognosis and increase in burden (Rai et al., 2016). The strengths of this is involving ADS patient group and evaluation DUI according to several diagnoses. We also found that diagnoses which are associated with higher chances of gross behavioural disturbances have a better chance to be brought to psychiatrist early, although the first contact remains magico-religious. Limitation are regarding more precise information made available from the patients or caretakers themselves. A future direction would by a face to face interview to find out further details of pathway to care and to follow them up prospectively.

\section{CONCLUSION}

DUI remain lengthy in India and is correlated with occupation, residence and most strongly with diagnosis. It took about 5 years on average to reach a psychiatric facility. This was even higher in patients with ADS. As, mentioned, this often lead to poorer prognosis. Awareness regarding illness model of ADS and other psychiatric disorders along treatment availability may improve DUI and lead to a better prognosis.

\section{REFERENCES}

Enoch, M.-A., \& Goldman, D. (2002). Problem Drinking and Alcoholism: Diagnosis and Treatment. Am Fam Physician, 65(3), 441.

Grover, S., Gupta, S., Mahajan, S., \& Avasthi, A. (2016). Pathway of care among patients with Dhat syndrome attending a psychosexual clinic in tertiary care center in North India. Ind Psychiatry J, 25(1), 72.

Gupta, S. K. (2012). Web model of pathways to psychiatric care for Indian setting. Int J Health Allied Sci, 1(4), 293.

Jain, N., Gautam, S., Jain, S., Gupta, I. D., Batra, L., Sharma, R., \& Singh, H. (2012). Pathway to psychiatric care in a tertiary mental health facility in Jaipur, India. Asian J Psychiatr, 5(4), 303-308.

Jeyashree, K., Sinha, S., \& Patro, B. K. (2013). Pathway to care of epilepsy patients: Exploratory study from an urban slum in Northern India. Ann Ind Acad Neurol, 16(3), 357.

Lahariya, C., Singhal, S., Gupta, S., \& Mishra, A. (2010). Pathway of care among psychiatric patients attending a mental health institution in central India. Indian J Psychiatry, 52(4), 333-338.

McGlashan, T. H. (1999). Duration of untreated psychosis in first-episode schizophrenia: Marker or determinant of course? Biol Psychiatry, 46(7), 899-907.

Rai, N., Prasad, K., Bhatia, R., Vibha, D., Singh, M. B., Rai, V. K., \& Kumar, A. (2016). Development and implementation of acute stroke care pathway in a tertiary care hospital in India: A cluster-randomized study. Neurol India, 64(7), 39.

Rehm, J., \& Shield, K. D. (2019). Global Burden of Disease and the Impact of Mental and Addictive Disorders. Curr Psychiatry Rep, 21(2), 10.

Sagar, R., Dandona, R., Gururaj, G., Dhaliwal, R. S., Singh, A., Ferrari, A., Dua, T., Ganguli, A., Varghese, M., Chakma, J. K., Kumar, G. A., Shaji, K. S., Ambekar, A., Rangaswamy, T., Vijayakumar, L., Agarwal, V., Krishnankutty, R. P., Bhatia, R., Charlson, F., ... 
Dandona, L. (2020). The burden of mental disorders across the states of India: The Global Burden of Disease Study 1990-2017. Lancet Psychiatry, 7(2), 148-161.

Sahu, A., Patil, V., Purkayastha, S., Pattanayak, R. D., \& Sagar, R. (2019). Pathways to care for patients with Bipolar-I disorder: An exploratory study from a tertiary care centre of North India. Indian J Psychol Med, 41(1), 68.

Salins, N., Johnson, J., \& Macaden, S. (2017). Feasibility and acceptability of implementing the integrated care plan for the dying in the Indian setting: Survey of perspectives of indian palliative care providers. Indian J Palliat Care, 23(1), 3.

Sartor, C. E., Lynskey, M. T., Bucholz, K. K., Madden, P. A. F., Martin, N. G., \& Heath, A. C. (2009). Timing of First Alcohol Use and Alcohol Dependence: Evidence of Common Genetic Influences. Addiction (Abingdon, England), 104(9), 1512-1518.

Schrijvers, G., van Hoorn, A., \& Huiskes, N. (2012). The care pathway: Concepts and theories: an introduction. Int J Integr Care, 12(Special Edition Integrated Care Pathways).

Singh, S., Kumar, E., Saroj, R., Satapathy, A., Nanjayya, S., \& Sharma, A. (2018). Pathways to Care in Patients approaching Community Mental Health Satellite Clinics in North India. J Postgraduate Med Education Res, 52, 12-15.

\section{Acknowledgements}

The author appreciates all those who participated in the study and helped to facilitate the research process.

\section{Conflict of Interest}

The author declared no conflict of interest.

How to cite this article: S B Nayok, Sathyanarayana MT \& D Akshatha H.S. (2020). Duration of untreated psychiatric illness and its correlations in patients attending a tertiary care psychiatric facility: a cross-sectional study. International Journal of Indian Psychology, 8(2), 36-42. DIP:18.01.005/20200802, DOI:10.25215/0802.005 